\title{
Assessing the Knowledge Regarding Prevention and Transmission of COVID-19 among Dental Healthcare Professionals in India
}

\author{
Shiladitya $\mathrm{Sil}^{1}{ }^{\circ}$, Suryoday Ghosh ${ }^{2}$
}

\begin{abstract}
Background and aim of the study: The nomenclature of COVID-19 was given by the World Health Organization on February 11, 2020. As dentists work in close proximity to the oral cavity, they remain at a high risk of exposure to COVID-19. With this background, a descriptive, cross-sectional questionnaire-based study was planned to assess the knowledge regarding prevention and transmission of COVID-19 among dental practitioners in India.

Materials and methods: A self-validated, 28-point questionnaire was formulated after reviewing the international guidelines and circulated through the Google Forms platform. Data were studied to establish a baseline.

Results: A total of 200 dental practitioners participated. Most of them had adequate knowledge regarding symptoms and transmission of COVID-19, directly proportional to higher degree and years of practice. There was adequate knowledge regarding sterilization protocols, disinfection techniques, and elective procedures with an overall score of $77.4 \%$. There was poor understanding of emergency dental procedures and patient and personnel screening. Indian dental practitioners were found to have adequate understanding of COVID-19 that is the need of the hour to break the chain of transmission.

Conclusion: There is a need to generate a set of guidelines and treatment protocols approved by national dental associations for the systematic functioning of dental practitioners in India.

Keywords: Coronavirus, COVID-19, Dental practice, Virology, Knowledge among dental surgeons, Dental Practitioners, India, Oral health care professionals.

Journal of Oral Health and Community Dentistry (2021): 10.5005/jp-journals-10062-0121
\end{abstract}

\section{INTRODUCTION}

The global pandemic of coronavirus disease-19 (COVID-19) was first reported in Wuhan province in the People's Republic of China in late December 2019. It is a member of the corona virus family like the systemic acute respiratory syndrome corona virus (SARS CoV) or Middle Eastern respiratory syndrome corona virus 9 (MERS CoV9) which were seen earlier, but a more virulent form of ribonucleic acid (RNA) virus causing lower respiratory tract illness. ${ }^{1,2}$ In severe cases, renal failure and death are also seen in COVID-19 cases. ${ }^{2,3}$ Globally, there is an increase in the number of COVID-19 patients daily and is at the 3.2 million mark, with 2.3 lakh fatalities, as on date. ${ }^{3}$ In India, there are about 26,000 active COVID-19 cases with a mortality rate of $3.3 \%$ and recovery rate of about $25 \% .{ }^{4}$

The main modes of transmission of COVID-19 are contact transmission, droplet transmission, and person-to-person transmission. ${ }^{5}$ Therefore, dental healthcare professionals (DHP) will be playing a role in the spread of infection as they come in contact with the patient's saliva, over and above, the aerosol which is produced during various routine dental procedures, such as scaling, polishing or using the airotor. ${ }^{6-8}$ Thus, air-borne contamination can happen from dental instruments, saliva, respiratory sources, and the operative site, thereby endangering the dental healthcare staff, their families, and society. ${ }^{8}$

In light of the modes of transmission and its alarming rate of transmission with increasing mortality, it is increasingly important for DHPs to have a proper and thorough knowledge about the preventive measures that can be employed to break the chain
${ }^{1}$ Department of Dentistry, Burdwan Medical College and Hospital, Bardhaman, West Bengal, India

${ }^{2}$ DEIC, Bankura Sammilani Medical College and Hospital, Bankura, West Bengal, India

Corresponding Author: Shiladitya Sil, Department of Dentistry, Burdwan Medical College and Hospital, Bardhaman, West Bengal, India, e-mail: shiladitya.sil@gmail.com

How to cite this article: Sil S, Ghosh S. Assessing the Knowledge Regarding Prevention and Transmission of COVID-19 among Dental Healthcare Professionals in India. J Oral Health Comm Dent 2021;15(3):139-143.

Source of support: Nil

Conflict of interest: None

of COVID-19 transmission. Due to the unique nature of COVID 19, there is not much data and literature available in this time frame. In a heavily populated country like India, prevention of transmission is the best method to deal with the pandemic as the healthcare facilities are already overburdened.

Hence there is a need to assess the knowledge of COVID-19 and the prevention of its transmission, especially among DHPs.

\section{Materials and Methods}

A descriptive, cross-sectional survey was conducted between March 15 and April 14, 2020 to assess the knowledge of DHPs regarding the prevention of COVID-19 outbreak. The study consisted of 200

(c) The Author(s). 2021 Open Access This article is distributed under the terms of the Creative Commons Attribution 4.0 International License (https://creativecommons. org/licenses/by-nc/4.0/), which permits unrestricted use, distribution, and non-commercial reproduction in any medium, provided you give appropriate credit to the original author(s) and the source, provide a link to the Creative Commons license, and indicate if changes were made. The Creative Commons Public Domain Dedication waiver (http://creativecommons.org/publicdomain/zero/1.0/) applies to the data made available in this article, unless otherwise stated. 
practicing dentists in India registered under the Dental Council of India. Purposive and chain referral sampling were used to achieve the sample size. The questionnaire of the survey was prepared after reviewing pertinent literature and international guidelines. ${ }^{9-11}$ After obtaining ethical approval, data collection was made using an online questionnaire provided by the Google Forms platform. The use of anonymous questionnaires maintained the privacy and confidentiality of all information collected in the study.

The self-validated questionnaire, which was structured with 28 multiple-choice questions with a single correct response, was devised in English. It was divided into sections: DHPs' demographic and profession-related characteristics (5 questions), DHPs' knowledge, regarding the transmission of the COVID-19, and infection control measures for preventing COVID-19 (23 questions, each carrying a score of 1 for correct and 0 for incorrect response, hence maximum score of 23).

The data were tabulated and studied to establish a baseline knowledge regarding transmission and infection control protocols for the prevention of COVID-19 among DHPs in India. The scores obtained were categorized into poor, fair, good, and excellent (Figure 1) and comparison was done among demographic groups of variables to draw inferences.

\section{Results}

Table 1 shows the distribution of the respondents according to their demographic details. Figure 1 depicts the percentage distribution of the 200 respondents according to the various grades depending on the score obtained, where majority of the respondents have good score (48\%) or excellent score (31\%). The mean score in our study was 17.80 out of 23.00 (77.4\%) which too as per the gradation, is a good score.

Table 2 reveals that the female respondents have a higher mean score (18.04) than male respondents (17.53), and greater number of female respondents (35) have excellent scores as compared to male respondents (27).

As per the age-group of the DHPs, there is an increase in the mean score from the lowest for 21-30 years (15.58) followed by $31-40$ years (18.77) and $41-50$ years (19.13), which is the highest mean score, after which there is a decline in mean score for 51-60 years (18.18) and above 60 years (16.50) as shown in Table 2.

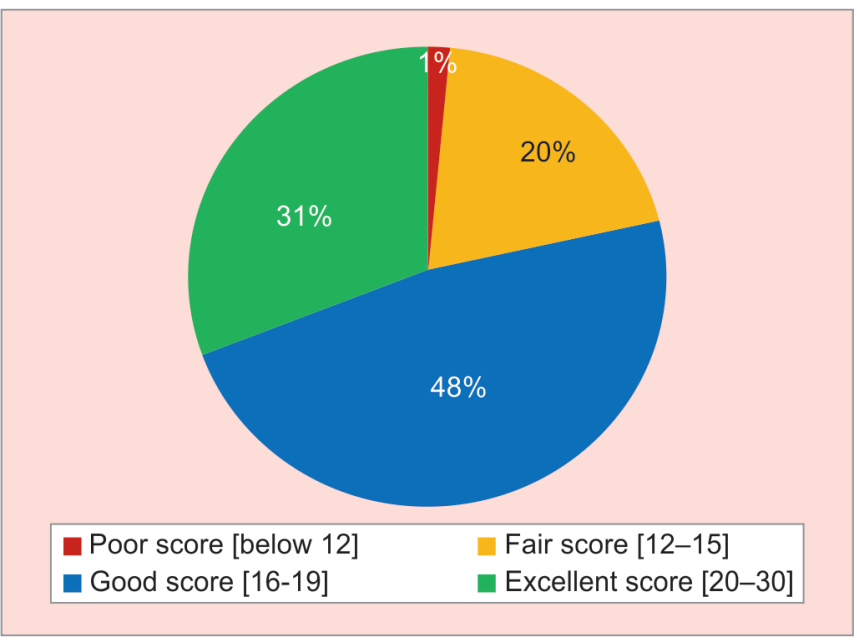

Fig. 1: Represents the grading system used in the study and the distribution of the DHPs according to their score
Table 1: Showing the distribution of demographic details of the DHPs included in the study

\begin{tabular}{lcc}
\hline Demographic variables & Value $(\mathrm{N})$ & Percentage $(\%)$ \\
\hline Gender & & \\
Male & 100 & 50.0 \\
Female & 100 & 50.0 \\
Age-group & & \\
21-30 years & 53 & 26.5 \\
31-40 years & 66 & 33.0 \\
41-50 years & 38 & 19.0 \\
51-60 years & 33 & 16.5 \\
Above 60 years & 10 & 5.0 \\
Qualification & & \\
BDS & 100 & 50.0 \\
MDS & 100 & 50.0 \\
Type of Practice & & \\
Independent practitioner & 124 & 62.0 \\
Consultant in a clinic & 26 & 13.0 \\
Works in a dental/medical institution & 50 & 25.0 \\
Years of Practice & & \\
0-5 years & 53 & 26.5 \\
6-10 years & 44 & 22.0 \\
11-15 years & 47 & 23.5 \\
16-20 years & 30 & 15.0 \\
Above 20 years & 26 & 13.0 \\
\hline
\end{tabular}

In case of qualification, MDS degree holders have a higher mean score (20.02) than BDS degree holders (15.55). All postgraduates have either good scores (38\%) or excellent scores (62\%) whereas majority of graduates have good scores (57\%) as shown in Table 2.

In this study, independent practitioners are seen to have the highest mean score (18.04), followed by institutional practitioners (17.96), with the least mean score for only consultant practitioners (17.22), though the mean score of all three groups are graded as good as shown in Table 2.

The highest mean score is seen for 11-15 years of practice (19.34) whereas the lowest mean score is seen for less than 5 years of practice (15.58). The remaining three groups have a mean score in the range of 18-19 and are graded as good scores as well as shown in Table 2.

Table 3 depicts the percentage of respondents who gave correct responses to the given question. Questions regarding COVID-19, it being declared a pandemic, its modes of transmission, outcome of the disease, and the isolation of COVID-19 patients had an overwhelming $100 \%$ response. Similarly, all DHPs in our study ensured proper fitting of the mask and disinfection of dental chair, equipment, and contaminated surfaces.

In all $86 \%$ of DHPs knew about the symptoms, $57 \%$ were sure about the incubation period, $63 \%$ were aware about its spread as well as hand washing duration, and $64 \%$ were particular regarding keeping the waiting area less crowded. About $69 \%$ knew about transmission during the asymptomatic stage whereas awareness regarding proper mask was $75 \%$, proper face shield was $63 \%$, and proper apron was $61 \%$, respectively as shown in Table 3.

It was observed that $65 \%$ were treating emergency patients, $96.5 \%$ were using personal protective equipment (PPE) for the same, and $95.5 \%$ gave utmost priority to travel and contact history, as well 
Knowledge about COVID-19 Prevention among Dentists

Table 2: Number of respondents for each grade along with the mean score for each group

\begin{tabular}{|c|c|c|c|c|c|c|}
\hline Demographic variables & $\begin{array}{l}\text { Total } \\
N(\%)\end{array}$ & $\begin{array}{c}\text { Poor score } \\
n(\%)\end{array}$ & $\begin{array}{c}\text { Fair score } \\
n(\%)\end{array}$ & $\begin{array}{c}\text { Good score } \\
n(\%)\end{array}$ & $\begin{array}{c}\text { Excellent score } \\
n(\%)\end{array}$ & $\begin{array}{l}\text { Mean } \\
\text { score }\end{array}$ \\
\hline \multicolumn{7}{|l|}{ Gender } \\
\hline Male & $100(100.0)$ & $2(2.0)$ & $24(24.0)$ & $47(47.0)$ & $27(27.0)$ & 17.53 \\
\hline Female & $100(100.0)$ & $1(1.0)$ & $16(16.0)$ & $48(48.0)$ & $35(35.0)$ & 18.04 \\
\hline \multicolumn{7}{|l|}{ Age-group } \\
\hline 21-30 years & $53(100.0)$ & $3(5.7)$ & $23(43.4)$ & $27(50.9)$ & $0(0.0)$ & 15.58 \\
\hline $31-40$ years & $66(100.0)$ & $0(0.0)$ & $10(15.1)$ & $24(36.4)$ & $32(48.5)$ & 18.77 \\
\hline $41-50$ years & $38(100.0)$ & $0(0.0)$ & $0(0.0)$ & $20(52.6)$ & $18(47.4)$ & 19.13 \\
\hline $51-60$ years & $33(100.0)$ & $0(0.0)$ & $0(0.0)$ & $24(72.7)$ & $9(27.3)$ & 18.18 \\
\hline Above 60 years & $10(100.0)$ & $0(0.0)$ & $7(70.0)$ & $0(0.0)$ & $3(30.0)$ & 16.50 \\
\hline \multicolumn{7}{|l|}{ Education } \\
\hline BDS & $100(100.0)$ & $3(3.0)$ & $40(40.0)$ & $57(57.0)$ & $0(0.0)$ & 15.55 \\
\hline MDS & $100(100.0)$ & $0(0.0)$ & $0(0.0)$ & $38(38.0)$ & $62(62.0)$ & 20.02 \\
\hline \multicolumn{7}{|l|}{ Type of Practice } \\
\hline Independent Practitioner & $124(100.0)$ & $3(2.5)$ & $23(18.5)$ & $53(42.7)$ & $45(36.3)$ & 18.04 \\
\hline Consultant in a Clinic & $26(100.0)$ & $0(0.0)$ & $0(0.0)$ & $26(100.0)$ & $0(0.0)$ & 17.22 \\
\hline $\begin{array}{l}\text { Works in a dental/medical } \\
\text { institution }\end{array}$ & $50(100.0)$ & $0(0.0)$ & $17(34.0)$ & $16(32.0)$ & $17(34.0)$ & 17.96 \\
\hline \multicolumn{7}{|l|}{ Years of Practice } \\
\hline $0-5$ years & $53(100.0)$ & $3(5.7)$ & $23(43.4)$ & $27(50.9)$ & $0(0.0)$ & 15.58 \\
\hline $6-10$ years & $44(100.0)$ & $0(0.0)$ & $10(22.8)$ & 17 (38.6) & $17(38.6)$ & 18.32 \\
\hline $11-15$ years & 47 (100.0) & $0(0.0)$ & $0(0.0)$ & $20(42.6)$ & $27(57.4)$ & 19.34 \\
\hline $16-20$ years & $30(100.0)$ & $0(0.0)$ & $0(0.0)$ & $24(80.0)$ & $6(20.0)$ & 18.10 \\
\hline Above 20 years & $26(100.0)$ & $0(0.0)$ & 7 (26.9) & 7 (26.9) & $12(46.2)$ & 18.19 \\
\hline
\end{tabular}

The mean score had a $p$ value $<0.05$ in all the parameters implying that they were statistically significant

as relevant symptoms of both patient and accompanying person. Safe medical waste disposal protocols were being followed by $92 \%$ respondents as shown in Table 3.

Only $43.5 \%$ respondents were cognizant of the high-risk dental procedures amid COVID-19 outbreak, and 45\% followed a day-today preliminary screening and monitoring of the office staff as shown in Table 3.

\section{Discussion}

This survey gives an insight into the current status of knowledge of DHPs regarding the prevention of transmission of COVID-19 in India. Though the importance of infection control is indispensible in regular practice, it has become undeniably paramount amid the COVID-19 outbreak. Only $1 \%$ of the study population had poor scores as compared to $48 \%$ and $31 \%$ having excellent and good scores, respectively, which shows adequate understanding among the DHPs that is essential amid the COVID-19 outbreak to prevent community transmission. An overall mean score of $77.4 \%$ was recorded in our study, which is higher as compared to Gupta et al. (the Zika virus (ZIKV) pandemic; 38.2\% among Indian dentists), Shivlingesh et al. (the influenza A (H1N1) outbreak; $52.6 \%$ of the Indian population), and Singh et al. (the ZIKV outbreak; $61.7 \%$ among the students of a dental institute). ${ }^{12-14}$ This may be attributed to the widespread availability of updated information from news and social media platforms alongside official guidelines to combat COVID-19 till a more definitive treatment strategy can be devised.

This study reflects the near equality in the mean score between male and female DHP, with females having an edge over males (Table 2). An interesting observation amidst the COVID-19 outbreak was that males were more commonly affected. Cai et al. attributed this particular finding to a difference in hormonal expression between the males and females. ${ }^{15}$

There is an increase in scores from 21 years to 50 years of age but a decrease there after (Table 2). This could be because the primary mode of education amid COVID-19 outbreak is by digital means; thus younger DHPs might be having an edge due to increased ease and dexterity in handling digital platforms. However, the difference in score is negligible and the mean score is graded good for all the age-groups.

Postgraduates have significantly higher mean scores than the graduates (Table 2), which is in conjunction to the studies done during the ZIKV and Ebola hemorrhagic fever pandemics. ${ }^{12,16}$ This may be attributed to the evidence-based practice and special training regarding infection control that is incorporated in the postgraduate curriculum.

A DHP who is a visiting consultant has lesser mean score (Table 2). This may be due to the fact that the infection control protocols are mostly followed by the clinical staff of institutions that they visit and the numbers of respondents from this group are also fewer in number. The same hypothesis can be applied 
Table 3: Percentage of respondents for each question in the survey

\begin{tabular}{|c|c|c|}
\hline Q No & Question asked & $\begin{array}{l}\text { Percentage of } \\
\text { correct response }\end{array}$ \\
\hline 6 & Have you heard of 2019 novel corona virus (COVID-19)? & 100.0 \\
\hline 7 & World Health Organization has declared the COVID-19 as: & 100.0 \\
\hline 8 & COVID-19 is transmitted through all modes except: & 100.0 \\
\hline 9 & Main symptoms of COVID-19 includes all except: & 86.0 \\
\hline 10 & COVID-19 can also lead to: & 100.0 \\
\hline 11 & Incubation period of COVID-19 ranges: & 57.0 \\
\hline 12 & Prevention of COVID-19 transmission is possible by all means except: & 100.0 \\
\hline 13 & In a dental office, the highest risk for spread of COVID-19 infection is through: & 43.5 \\
\hline 14 & COVID-19 can spread through: & 63.0 \\
\hline 15 & What should be the recommended duration of handwashing to prevent cross-infection by COVID-19? & 63.0 \\
\hline 16 & During the COVID-19 outbreak are you treating patients? & 65.0 \\
\hline 17 & With regard to the above question, do you use Personal Protective Equipment (PPE)? & 96.5 \\
\hline 18 & $\begin{array}{l}\text { During the COVID-19 outbreak, preliminary screening and monitoring of symptoms of all clinical staffs } \\
\text { should be done: }\end{array}$ & 45.0 \\
\hline 19 & $\begin{array}{l}\text { Amid the COVID-19 outbreak, crowding in the patient waiting area can be allowed as most of the } \\
\text { clinics are closed. }\end{array}$ & 64.0 \\
\hline 20 & COVID-19-infected patients should be kept in isolation. & 100.0 \\
\hline 21 & $\begin{array}{l}\text { Amid the COVID-19 outbreak, before the commencement of examination, recording of travel history, } \\
\text { contact history, history of symptoms is necessary for every patient and accompanying person. }\end{array}$ & 95.5 \\
\hline 22 & Persons with COVID-19 cannot infect others when they are asymptomatic. & 69.0 \\
\hline 23 & When wearing a mask, it is important to ensure that it fits properly. & 100.0 \\
\hline 24 & What type of mask is preferred in the COVID-19 outbreak? & 75.0 \\
\hline 25 & Amid the COVID-19 outbreak, usage of goggles and face shield is incorporated in practice. & 63.0 \\
\hline 26 & Amid the COVID-19 outbreak, which type of apron is preferred? & 61.0 \\
\hline 27 & $\begin{array}{l}\text { Disinfection of the dental chair, dental equipment, and other contaminated surfaces is required } \\
\text { between patients. }\end{array}$ & 100.0 \\
\hline 28 & $\begin{array}{l}\text { Amid the COVID-19 outbreak, proper and timely disposal of waste in a closed bin and labeled as } \\
\text { "infectious medical waste" is done with utmost importance. }\end{array}$ & 92.0 \\
\hline
\end{tabular}

to the institutional practitioners as well, and the collective institutional resources might lead them in having an edge over visiting consultants. The self-handling of managerial activities in the clinic might lead to a more detailed idea about functioning and infection control protocols, aiding independent practitioners to have a better understanding of the same and thus record the highest mean score.

Due to lesser experience in terms of practicing years, DHPs with less than 5 years of experience have lesser knowledge as compared to other greater experience groups, who have more or less the similar mean scores. This can be attributed to the longer practice experience.

The most important approach in tackling a pandemic like COVID-19 is having the currently available knowledge which has to be updated on a regular basis as there are constantly emerging facts that can define disaster aversion and management strategies. Due to the lack of definitive treatment, prevention of transmission is of utmost importance, especially in a country like India. In our study, all DHPs had adequate knowledge of the disease, its symptoms and modes of transmission, and the role of social distancing and isolation as opposed to previous documentation during Zika virus outbreak. ${ }^{12,14}$ This can be due to the readily available global guidelines and protocols to prevent the spread of COVID-19.

The people who come in close contact with an infected individual or are in close proximity to or work near the patient, that is, relatives and healthcare workers, are at a higher risk of contracting the virus. The working field for a DHP is approximately $35-40 \mathrm{~cm}$, mostly involving aerosol and splatter while certain procedures can be very time-consuming, which puts the DHPs at a higher risk. ${ }^{1,6,17}$ Thus, knowledge regarding high-risk procedures (43.5\%) and treating emergency cases (65\%) are the precise areas that need to be addressed while educating DHPs through continuing dental education programs and webinars. Moreover, close proximity to patients, lengthy appointments, along with procedural aerosol and splatter demand the use of PPE, masks, face shields, and aprons in regular practice amid the outbreak. This challenges the dental practice financially in Indian economic scenario, especially the young and/or independent practitioners. ${ }^{6,18}$ Although in the abovementioned aspect the results extrapolate to greater than $60 \%$ of the study population having adequate knowledge regarding infection control in the clinical setting, it can be increased by providing educational as well as financial support from the national and regional government authorities to combat the personal, financial, and social challenges.

In order to prevent transmission and cross-infection of COVID-19 in dental healthcare setting, firstly, utmost importance has to be given to travel and contact history. Leder et al. reported travellerassociated infections (especially respiratory infections), which is evident for transmission of COVID-19 as well. ${ }^{19}$ In the present study, $95.5 \%$ of the DHPs included the travel and contact history of the 
patient and the accompanying person to rule out asymptomatic carriers, thereby preventing further propagation of infection. ${ }^{19-21}$ Secondly, proper sterilization and disinfection protocols have to be followed between two patient consultations along with proper waste disposal; above $90 \%$ of the respondents were abiding by such norms in our study. ${ }^{18}$ Thirdly, regular preliminary screening and symptomatic monitoring of staff is of paramount importance whereas it is conducted by only $45 \%$ of DHPs in our survey; this leads to a knowledge deficit that needs to be bridged by webinars and educational programs. ${ }^{1,18,22}$ Finally, $64 \%$ of the DHPs agreed to avoid crowding of the clinic to ensure social distancing along with the opportunity to get proper disinfection and sterilization done. ${ }^{22}$

Delineating the potential limitations of the present survey is important. The self-reported nature of the information might make the interpretation of actual practices differ from reported practices, hinting on social desirability biases, which in turn may permit respondents to over-report or under-report attitude and exercise. Usage of the online platform for data collection is also responsible for coverage error, which had to be allowed during this pandemic. Another limitation is the self-selection bias on the side of the respondents due to convenience sampling and snowball sampling. Thus in order to overcome such shortcomings, an educational model rather than an assessment of the current status has to be employed, followed by a post-program assessment, in order to strengthen the knowledge regarding prevention of transmission of COVID-19 from a dental office.

\section{Conclusion}

The present study revealed that the DHPs in India had adequate knowledge regarding the symptoms, prevention of transmission, and infection control of COVID-19 in dental clinic settings. The extra precautionary measures that could be pivotal in protecting the dental staff and other patients from COVID-19 had been comprehended by comparatively lesser number of DHPs. In order to overcome these deficits, educational study models need to be designed with an aim to update and enrich the present knowledge as newer facts and characteristics of COVID-19 unravel with time.

There is a need to generate a set of standardized protocols (approved by the respective state dental associations and the national dental council) and treatment algorithms to be followed by the DHPs in the clinic and hospital setting that will not only play an active role in the prevention of transmission of COVID-19 but also address the dental needs of the community at large and ensure adequate safety of the DHPs. Moreover, the regional and national dental associations should conduct webinars, provide moral and financial support amid the COVID-19 pandemic, and keep all DHPs well informed and aware of the best practices and recommended disease management approaches in this dire situation.

\section{ORCID}

Shiladitya Sil @ https://orcid.org/0000-0003-2131-1126

\section{References}

1. Meng L, Hua F, Bian Z. Coronavirus disease 2019 (COVID-19): Emerging and future challenges for dental and oral medicine. J Dent Res 2020; PMID: 32162995.

2. Del Rio C, Malani PN. 2019 Novel coronavirus-important information for clinicians. JAMA 2020. DOI: 10.1001/jama.2020.1490.

3. World Health Organization. Coronavirus disease 2019 (COVID-19). 2020: Situation Report-100. Accessed on April 30, 2020. Available from: https://www.who.int/docs/default-source/coronaviruse/ situation-reports/20200429-sitrep-100-covid-19.pdf

4. Ministry of Health and Family Welfare, Government of India. Available from: https://mohfw.gov.in [Accessed on April 30, 2020].

5. Ibrahim NK, Alwafi HA, Sangoof SO, et al. Cross-infection and infection control in dentistry: Knowledge, attitude and practice of patients attended dental clinics in King Abdulaziz University Hospital, Jeddah, Saudi Arabia. J Infec Pub Health 2017;10(4):438-445. DOI: 10.1016/ j.jiph.2016.06.002.

6. Harrel SK, Molinari J. Aerosols and splatter in dentistry: A brief review of the literature and infection control implications. J Am Dent Assoc. 2004;135(4): 429-437. DOI: 10.14219/jada.archive.2004.0207.

7. Sabino-Silva R, Jardim AC, Siqueira WL. Coronavirus COVID-19 impacts to dentistry and potential salivary diagnosis. Clin Oral Investig 2020. DOI: 10.1007/s00784-020-03248-x.

8. Corstjens PL, Abrams WR, Malamud D. Saliva and viral infections. Periodontol 2000 2016;70(1):93-110. DOI: 10.1111/prd.12112.

9. World Health Organization. Clinical management of severe acute respiratory infection when novel coronavirus $(\mathrm{nCoV})$ infection is suspected: Interim guidance 2020 [updated March 13, 2020]. Available from: https://www.who.int/publications-detail/clinical-managementofsevere-acute-respiratory-infection-when-novel-coronavirus(ncov)-infection-is-suspected.html.

10. Centers for Disease Control and Prevention (CDC). CDC developing guidance regarding responding to COVID-19 in dental settings. Division of Oral Health, National Center for Chronic Disease Prevention and Health Promotion 2020 [updated March 11, 2020]. Available from: https://www.cdc.gov/oralhealth/infectioncontrol/ statement-COVID.html.

11. American Dental Association (ADA). Coronavirus frequently asked questions 2020 [updated March 16, 2020].

12. Gupta N, Randhawa RK, Thakar S, et al. Knowledge regarding Zika virus infection among dental practitioners of Tricity area (Chandigarh, Panchkula and Mohali), India. Niger Postgrad Med J 2016;23(1):33-37. DOI: 10.4103/1117-1936.180179.

13. Shivlingesh KK, Agrawal A, Chaudhary $\mathrm{H}$, et al. Public knowledge, attitude and behavioural changes in an Indian population during the Influenza A (H1N1) outbreak. J Infect Dev Countries 2010;4(1):7-14. DOI: $10.3855 /$ jidc.501.

14. Singh M, Singh K, Puri MS, et al. Knowledge and perception towards Zika outbreak in a dental institute. Dent 2017;7(3):1000420. DOI: 10.4172/2161-1122.1000420.

15. Cai H. Sex difference and smoking predisposition in patients with COVID-19. The Lancet Resp Med 2020;8(4):e20. DOI: 10.1016/S22132600(20)30117-X.

16. Gupta N, Mehta N, Gupta P, et al. Knowledge regarding Ebola Hemorrhagic Fever among private dental practitioners in Tricity, India: A cross-sectional questionnaire study. Niger Med J 2015;56(2):138-142. Doi: 10.4103/0300-1652.153405.

17. Pîrvu C, Pătraşcu I, Pîrvu D, et al. The dentist's operating posture: Ergonomic aspects. J Med Life 2014;7(2):177-182. PMCID: PMC4151237.

18. Peng $X, X u X, L i Y$, et al. Transmission routes of $2019 \mathrm{nCoVand} \mathrm{controls}$ in dental practice. Int J Oral Sc 2020 Mar;12(1):1-6. DOI: 10.1038/ s41368-020-0075-9.

19. Duong TN, Waldman SE. Importance of a travel history in evaluation of respiratory infections. Curr Emerg Hosp Med Rep 2016;4(3):141-152. DOI: 10.1007/s40138-016-0109-y.

20. Fotedar S, Sharma KR, Bhardwaj V, et al. Precautions in dentistry against swine flu. SRM J Res Dent Sci 2013;4(4):161-163. DOI: 10.4103/0976-433X.125593.

21. Leder K, Torresi J, Libman MD, et al. GeoSentinel surveillance of illness in returned travelers, 2007-2011. Ann Intern Med 2013;158(6): 456-468. DOI: 10.7326/0003-4819-158-6-201303190-00005.

22. Spagnuolo G, De Vito D, Rengo S, et al. COVID-19 Outbreak: An overview on dentistry. Int J Environ Res Public Health 2020 March;17(6):2094. DOI: 10.3390/ijerph17062094.DOI: 10.3390/ijerph1 7062094. 